\title{
Coatings of $\mathrm{Fe}_{3} \mathrm{O}_{4}$ Nanoparticles as Selective Solar Absorber
}

\author{
Federico González ${ }^{1}$, Enrique Barrera-Calva ${ }^{*}, 1$ Lázaro Huerta ${ }^{2}$ and Rajaram S. Mane ${ }^{3}$ \\ ${ }^{1}$ Universidad Autónoma Metropolitana, Iztapalapa, Av. San Rafael Atlixco No. 186 Col. Vicentina, 09340 México D.F., \\ Mexico \\ ${ }^{2}$ Instituto de Investigaciones en Materiales, Universidad Nacional Autónoma de México, Circuito Exterior S/N, 04510, \\ México DF, México \\ ${ }^{3}$ Swami Ramanand Teerth Marathwada University, Nanded, India
}

\begin{abstract}
Cost-effective and pollution-free green chemical method has been employed for synthesizing $\mathrm{Fe}_{3} \mathrm{O}_{4}$ nanoparticles which can be used as a solar absorbent and characterized further for their structural, optical and morphological properties using X-ray diffraction and UV-VIS-IR spectrophotometry and transmission electron microscopy techniques, respectively. Presence of $\mathrm{Fe}^{2+}$ and $\mathrm{Fe}^{3+}$ in nanoparticles is confirmed from the X-ray photoelectron spectroscopy analysis. The nanometric grain-size allows deposition of thin films, and the resulting coatings onto copper substrate show a relatively low thermal emittance in a range of $0.05-0.10$. The solar absorptance values are between 0.76 and 0.85 , which can provide an acceptable selectivity. Attempt is also made to find influence of the thickness effect on the selectivity having 15.2 as best value for one layer coating.
\end{abstract}

Keywords: Nanometric $\mathrm{Fe}_{3} \mathrm{O}_{4}$, black coatings, solar absorber.

\section{INTRODUCTION}

Spectrally selective absorbers used in solar collectors are known to improve the efficiency of solar-to-thermal energy conversion process. A spectrally selective surface should have high absorbance for radiation in the solar energy spectrum $(0.3-2.5 \mu \mathrm{m})$ to capture the maximum solar energy, and low thermal emittance in the IR region $(2.5-25.0 \mathrm{~mm})$ to reduce energy losses. In other words, to enhance the total solar absorbance in the visible spectral region, the surface should have the lowest possible reflectance and, to suppress the thermal emittance, it should have the highest possible reflectance in the IR region. The spectrally selective surface invented by Tabor [1] is a tandem surface. The top layer is a solar absorbing coating which allows passing infrared radiations easily. The underlying metal surface contributes with a low thermal emittance for in-service temperatures of the solar collector. In turn, solar absorbing coating formation is a key step for photo-thermal conversion in a simple and reproducible way in solar collectors [2-5]. Furthermore, particle-size in the absorbing layer plays crucial role in achieving optimal spectral selectivity. Thicker coating generally produces a large thermal emittance and vice-versa. A sharp transition from a high absorbance in the solar range to low emittance in the infrared range is obtained with thin film interference which restrains $100-500 \mathrm{~nm}$ thickness [6]. Additionally, it is quiet accepted that the smaller particles avoid scattering.

Despite the widespread research on the synthesis [7-12] and potential applications of nanometric iron oxide $\left(\mathrm{Fe}_{3} \mathrm{O}_{4}\right)$

*Address correspondence to this author at the Universidad Autónoma Metropolitana, Iztapalapa, Av. San Rafael Atlixco No. 186 Col. Vicentina, 09340 México D.F., Mexico; Tel: + 5255 58044644; Fax: + 5255 58044649; E-mail: ebc@xanum.uam.mx in biomedical [13, 14], spintronics [8], plasmonic [15], gas sensing [16], etc.; work on with the solar absorbing coating of $\mathrm{Fe}_{3} \mathrm{O}_{4}$ nanoparticles is practically limited [17-19]. With best of our knowledge and experience in this field, till date, no report exists on the solar absorbing $\mathrm{Fe}_{3} \mathrm{O}_{4}$ nanoparticles coating. Therefore, in this work we explore, for the first time, the potential use of $\mathrm{Fe}_{3} \mathrm{O}_{4}$ nanoparticles synthesized via a green synthesis method as a solar absorber coating and further characterization for structural, optical, morphological properties by means of various techniques.

\section{EXPERIMENTAL DETAILS}

\section{1. $\mathrm{Fe}_{3} \mathrm{O}_{4}$ Nanoparticles Synthesis and Film Formation}

All chemicals, preferred in the present study, were analytical reagent grade, and all solutions were prepared in deionized water as a solvent. Ferric chloride hexahydrate $\left(\mathrm{FeCl}_{3} 6 \mathrm{H}_{2} \mathrm{O}\right), \alpha$-D-glucose, $\mathrm{NH}_{4} \mathrm{OH}(25 \%$, w/w) were all purchased from Aldrich. The $\mathrm{Fe}_{3} \mathrm{O}_{4}$ nanoparticles were synthesized according to the following procedure. Initially, $10 \mathrm{~mL}$ of $0.05 \mathrm{M}$ glucose solution was added into $10 \mathrm{~mL}$ of aqueous solution containing $0.3 \mathrm{M} \mathrm{Fe}^{3+}$. The mixture was refluxed under mechanical stirring for $12 \mathrm{~h}$ at $90{ }^{\circ} \mathrm{C}$. Then, the mixture solution was added drop-wise into $50 \mathrm{~mL}$ of $1 \mathrm{M}$ $\mathrm{NH}_{4} \mathrm{OH}$ solution maintained at $\mathrm{pH} \sim 10$ under mechanical stirring for $30 \mathrm{~min}$ at $60^{\circ} \mathrm{C}$. The color of the suspension was turned into black immediately. The suspension was cooled to room temperature, and the sediment powder containing nanoparticles was separated from the suspension and washed five times with de-ionized water. Commercially available copper sheet of $1 \mathrm{~mm}$ thickness was cut into $10 \mathrm{~cm}^{2}$ pieces and used as substrates. In order to obtain uniform coatings, the copper surface was polished by using 1200-grade SiC paper. Then, the substrates were washed with de-ionized water and dried with gaseous $\mathrm{N}_{2}$. Following the cleaning step, the copper sheets were dipped into above-mentioned 
black suspension containing $\mathrm{Fe}_{3} \mathrm{O}_{4}$ nanoparticles. The dipping process was repeated for three times.

\subsection{Employed Characterization Techniques}

The powder of $\mathrm{Fe}_{2} \mathrm{O}_{4}$ nanoparticles was characterized by $\mathrm{X}$-ray diffractometry. The X-ray diffraction (XRD) patterns were obtained with a Bruker AXS D8 Advance diffractometer with the Bragg-Brentano $\theta-\theta$ geometry, $\mathrm{Cu}-$ $\mathrm{K} \alpha$ radiation, a graphite secondary-beam monochromator, and a punctual scintillation detector. The diffraction intensity as a function of $2 \theta$ was measured between $20-110^{\circ}$, with a $2 \theta$ step of $0.015^{\circ}$ for $0.6 \mathrm{~s}$ per point. Crystal structure was refined using the Rietveld method and the FullProf code [20]. Several samples were prepared onto a copper grid for the transmission electron microscopy (TEM) analysis and then observed in a Zeiss electron microscope model EM-910 operating at $120 \mathrm{kV}$. Chemical composition of powder was performed by X-ray photoelectron spectroscopy (XPS) technique, using an ultra-high vacuum system of VG Microtech ESCA2000 Multilab, equipped with a Al Ka Xray source $(1486.7 \mathrm{eV})$ and a multichannel detector analyzer. Prior to the XPS measurements, the powder was pressed to form a pellet.

The solar absorption $\left(\alpha_{\mathrm{s}}\right)$ and the thermal emittance $\left(\varepsilon_{\mathrm{th}}\right)$ of the coatings were determined by using the Duffie and Beckman approach [21]. The total hemispherical reflectance, between 0.3 and $2.5 \mu \mathrm{m}$ corresponding to the solar spectrum was recorded by using a Cary 5E spectrophotometer equipped with an integrating sphere operating in the reflectance mode. The thermal emittance was obtained from specular reflectance measurements in the infrared region (2.5-14 $\mu \mathrm{m})$ using a Nicolet 750 FTIR spectrometer. A gold mirror was employed as the $100 \%$ reflectance reference. An Ambios model QScope 253 atomic force microscope (AFM) in non-contact mode was used to investigate the surface morphology of the coatings. The RMS roughness and the height distribution were calculated from a statistics analysis of the experimental data.

\section{RESULTS AND DISCUSSION}

\subsection{Structural Elucidation and Compositional Confirmation}

Fig. (1) shows the XRD pattern of synthesized $\mathrm{Fe}_{3} \mathrm{O}_{4}$ nanoparticles which fitted well with the Bragg reflections (indicated by the thick marks in Fig. 1) of cubic magnetite phase, corresponding to the JCPDS file 19-629. A further analysis of the XRD data by Rietveld refinement allows us to calculate the value of the ' $a$ ' cell parameter which is 0.8374 $( \pm 0.0002) \mathrm{nm}$, and an average crystallite size of $7.1( \pm 1.9)$ $\mathrm{nm}$. The crystallite size confirmed the nanometric nature of $\mathrm{Fe}_{2} \mathrm{O}_{3}$ powder. For more detail, TEM image (Fig. 2) shows needle-like crystallites with length and diameter are $\sim 20 \mathrm{~nm}$ and $\sim 8 \mathrm{~nm}$, respectively. Therefore, both techniques corroborate the size of the particles, being nanometric.

\subsection{Elemental Analysis}

The elemental analysis and the relative composition of $\mathrm{Fe}^{3+}$ and $\mathrm{Fe}^{2+}$ were quoted using XPS measurement. The $\mathrm{Fe}_{3} \mathrm{O}_{4}$ is a mixed-valence compound with a conventional notation of $\left[\mathrm{Fe}^{3+}\right]_{\mathrm{tet}}\left[\mathrm{Fe}^{2+} \mathrm{Fe}^{3+}\right]_{\text {oct }} \mathrm{O}_{4}$. The survey scan XPS

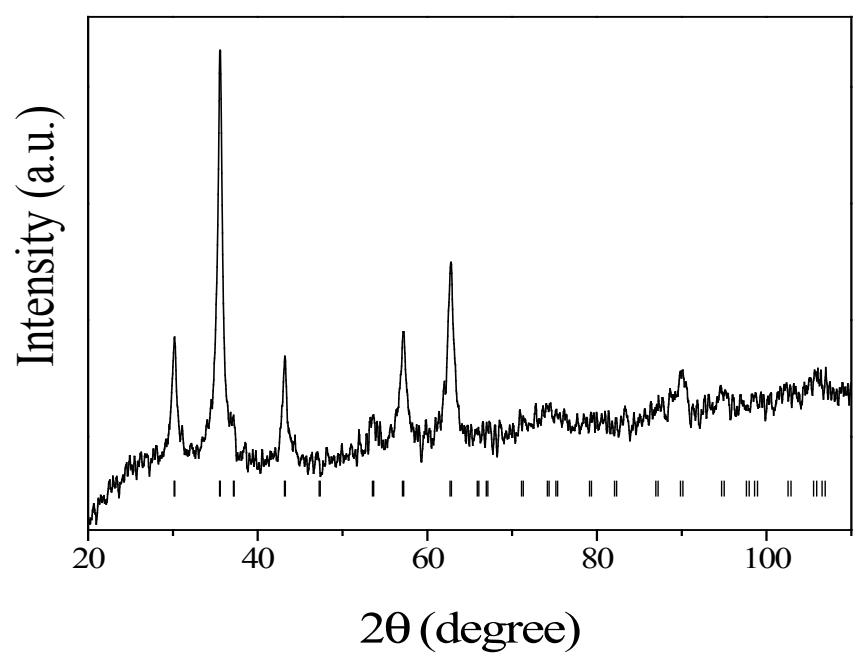

Fig. (1). The X-ray diffraction pattern of the $\mathrm{Fe}_{3} \mathrm{O}_{4}$ nanoparticles (the thick marks below the diffractogram, correspond to the Bragg reflections of magnetite).

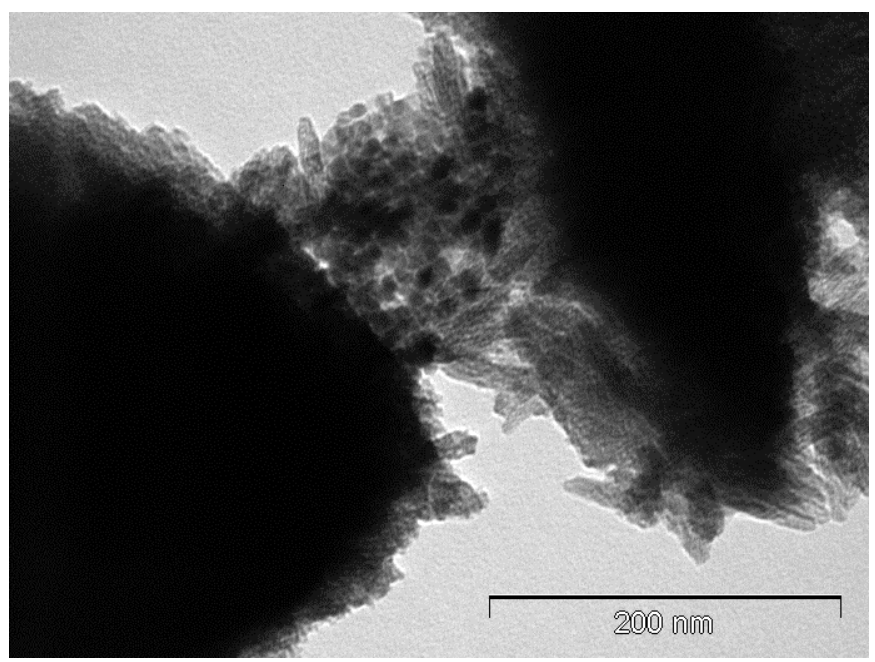

Fig. (2). The TEM (bright filed) image of $\mathrm{Fe}_{3} \mathrm{O}_{4}$ nanoparticles.

spectrum (Fig. 3) of the powder showed iron oxide with mixed-valence, discussed later. The appearance of $\mathrm{C} 1 \mathrm{~s}$ peak originates from the spectrometer rotary pump oil that inevitably contaminates the samples at working pressure $(1 \mathrm{x}$ $10^{-5} \mathrm{~Pa}$ ). In the present investigation, the chemical state of the constituent elements was determined by calculating the binding energy with reference to $\mathrm{C} 1 \mathrm{~s}$ peak at $284.9 \mathrm{eV}$ (identified thorough the spectrometer calibration). A different choice would change the actual value, but not the relative value. For comparison, standard $\mathrm{Fe}_{2} \mathrm{O}_{3}$ was also studied. The survey scan spectra also confirmed O1s peak, which is at about $529.9 \mathrm{eV}$, corresponding to oxide oxygen [22]. Fig. (4a) shows the XPS Fe2p core-level spectrum of the coating. The intensity of the main-peak shoulder of the $\mathrm{Fe} 2 \mathrm{p}_{3 / 2}$ at $709.6 \mathrm{eV}$, is characteristic of $\mathrm{Fe}^{2+}$ ions [23]. The binding energy at $710.5 \mathrm{eV}$ for the $\mathrm{Fe} 2 \mathrm{p}_{3 / 2}$ main peak is consistent with typical values for the ferric oxides [23] as it can be seen in the XPS spectrum of the $\mathrm{Fe}_{2} \mathrm{O}_{3}$ used as the reference (Fig. 4b). In the XPS spectrum of $\mathrm{Fe}_{3} \mathrm{O}_{4}$, the $2 \mathrm{p}_{3 / 2}$ satellite at $718.0 \mathrm{eV}$ characteristic of the $\mathrm{Fe}^{3+}$ ions in $\mathrm{Fe}_{2} \mathrm{O}_{3}$, becomes less resolved due to rising intensity at $715.2 \mathrm{eV}$. This latter intensity is normally assigned to the satellite for 
the $\mathrm{Fe}^{2+}$, analogous to the spectrum of wüstite $(\mathrm{FeO})$ [23] However, an additional contribution to this feature is $p$ - $d$ hybridization, due to the fact that the $\mathrm{Fe}-\mathrm{O}$ inter-atomic distance of the octahedral sites in bulk $\mathrm{Fe}_{3} \mathrm{O}_{4}$ is smaller than in bulk $\mathrm{FeO}$ [24]. An analogous analysis can be done for the $\mathrm{Fe} 2 \mathrm{p}_{1 / 2}$ region. The estimated relation between $\mathrm{Fe}^{3+}$ and $\mathrm{Fe}^{2+}$, calculated from the peak areas of the $\mathrm{Fe} 2 \mathrm{p}_{3 / 2}$ orbital, resulted 2:1, which is stoichiometric to the $\mathrm{Fe}_{3} \mathrm{O}_{4}$. Thus, the XPS study revealed the presence of $\mathrm{Fe}_{3} \mathrm{O}_{4}$.

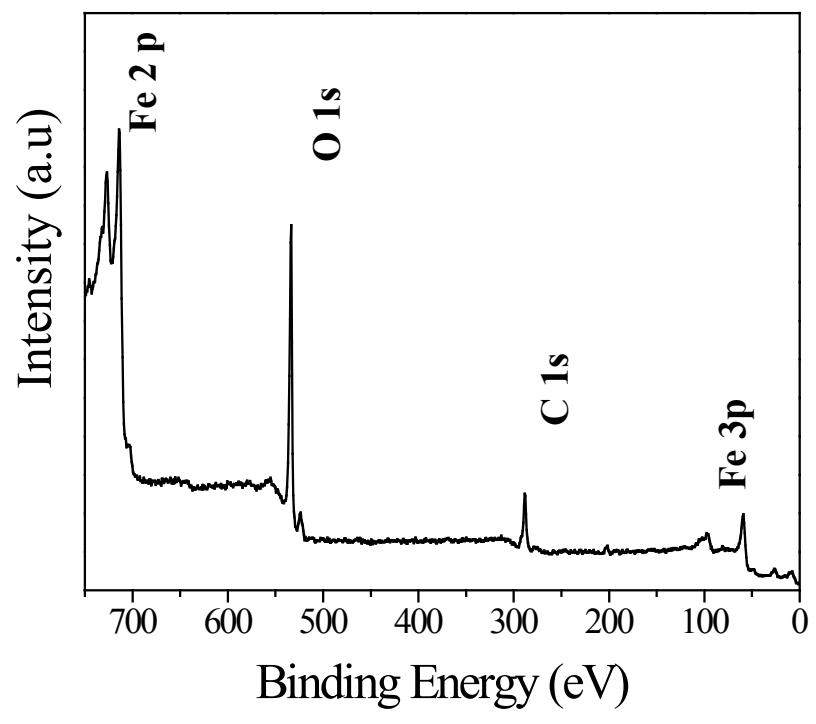

Fig. (3). Full-scan XPS spectra of a $\mathrm{Fe}_{3} \mathrm{O}_{4}$ nanoparticles powder.

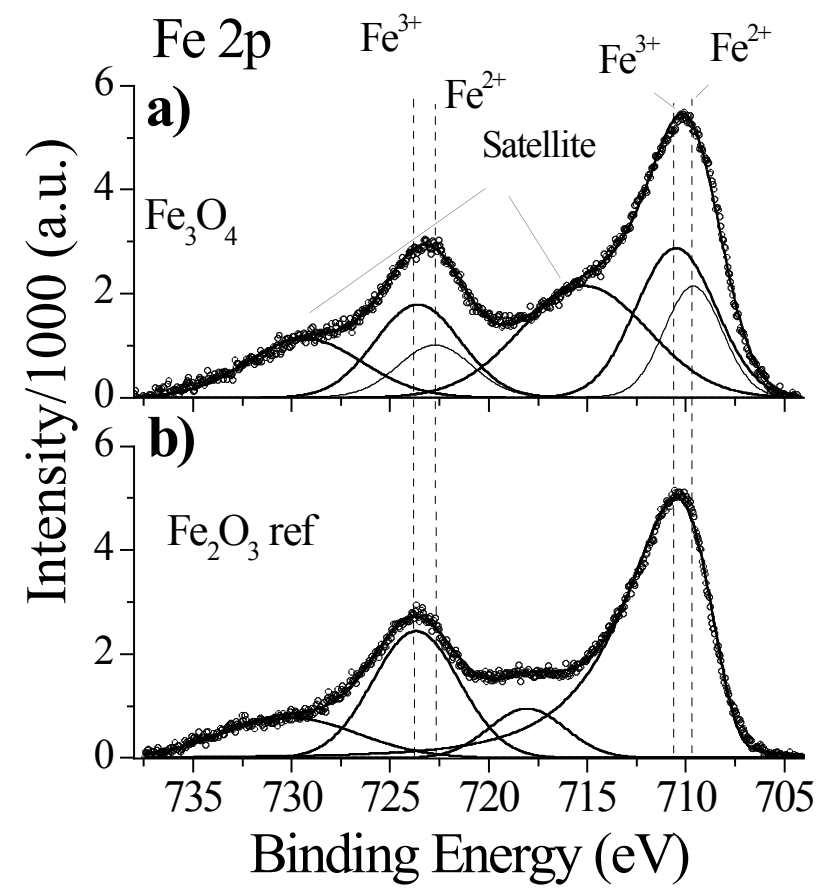

Fig. (4). The XPS Fe2p core-level spectra for; (a) $\mathrm{Fe}_{3} \mathrm{O}_{4}$ powder nanoparticles and (b) the reference standard $\mathrm{Fe}_{2} \mathrm{O}_{3}$.

\subsection{Morphological Evolution}

In Fig. (5a), an AFM image of $10 \times 10 \mu \mathrm{m}^{2}$ area of the coating during one dipping processor is shown whereas Gaussian distribution representing the statistics analysis of the height data is shown in a Fig. (5b). Importance of the relationship between "randomness" in surface and optical properties has been pointed out by us in a recent work [25]. The thin film thickness can be roughly estimated by the AFM image. It is around $0.7 \mu \mathrm{m}$. This estimation was made by assuming that the valleys are at the substrate level, which is reasonable considering that the $\mathrm{Fe}_{3} \mathrm{O}_{4}$ particles are suspended in the aqueous media.

a)
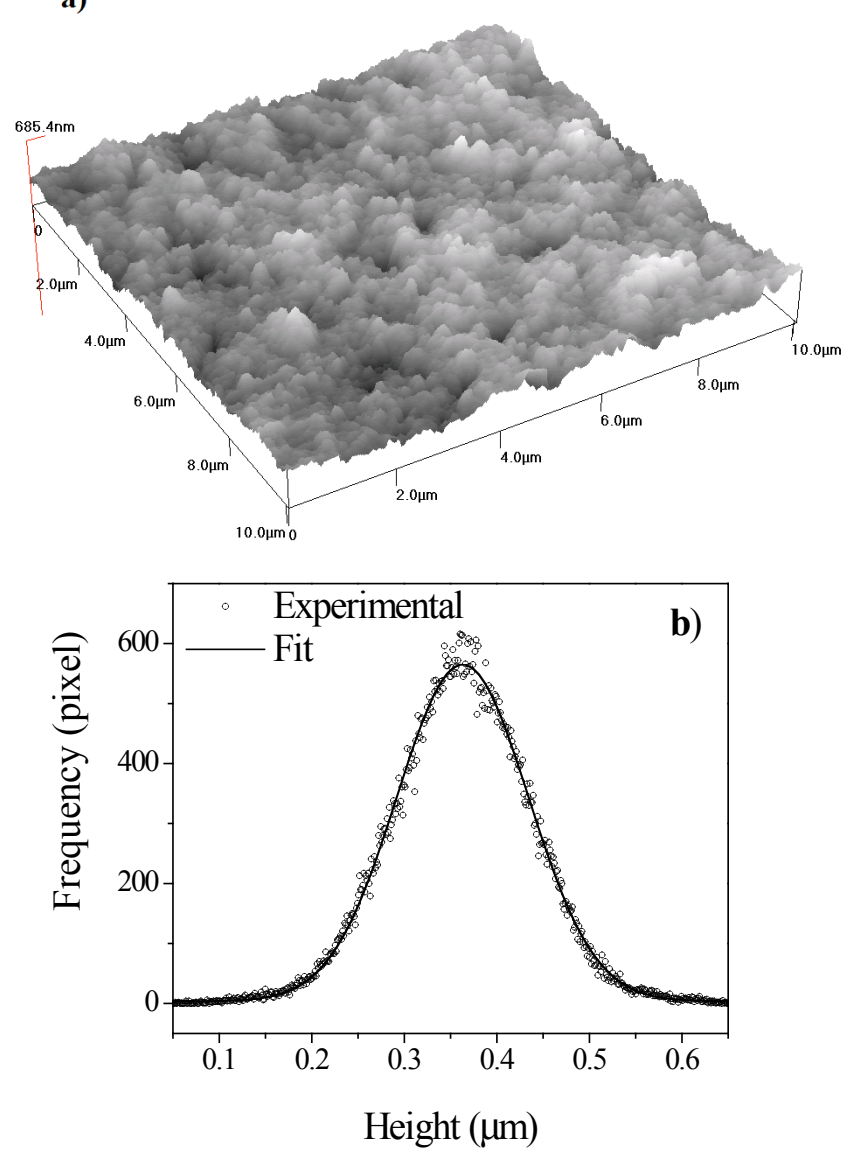

Fig. (5). (a) The AFM image of the coating (one dip) into $\mathrm{Fe}_{3} \mathrm{O}_{4}$ suspension on $\mathrm{Cu}$ substrate and (b) corresponding its eight histogram.

\subsection{Optical Studies}

The efficient conversion of solar energy to thermal energy is derived, mainly, from the optical properties of coatings as it is above-mentioned. According to law of Kirchhoff, in thermal equilibrium

$\alpha=\varepsilon$

where $\alpha$ and $\varepsilon$ are the absorptance and emittance, respectively. In general, the solar absorptance $\left(\alpha_{s}\right)$ and thermal emittance $\left(\varepsilon_{\mathrm{th}}\right)$ are surface related properties. The first one is defined as the fraction of all the solar radiation absorbed by the surface and the later one can be defined as the ratio of the radiation emitted by a surface to the radiation emitted by a blackbody at the same temperature. It is possible to show that it is necessary to know only one property, the reflectance. Fig. (6) show typical reflectance spectra of the $\mathrm{Fe}_{3} \mathrm{O}_{4} / \mathrm{Cu}$ one dip thin film. From it absorptance and emittance can be obtained. The useful relationship between reflectance and absorptance, which can be considered as a statement of conservation energy, is 
Table 1. Integrated Solar Absorptance, Thermal Emittance (at $373 \mathrm{~K}$ ), Selectivity and RMS Roughness of the Nanostructured $\mathrm{Fe}_{3} \mathrm{O}_{4} / \mathrm{Cu}$ Thin Film

\begin{tabular}{|c|c|c|c|c|}
\hline Number of Dips & Solar Absorptance & Thermal Emittance & Selectivity $\left(\boldsymbol{\alpha}_{\boldsymbol{s}} / \boldsymbol{\varepsilon}_{\mathrm{th}}\right)$ & RMS Roughness, $\check{\mathbf{A}}$ \\
\hline \hline 1 & 0.76 & 0.05 & 15.2 & 43 \\
\hline 2 & 0.82 & 0.07 & 11.7 & 47 \\
\hline 3 & 0.85 & 0.10 & 8.5 & 45 \\
\hline
\end{tabular}

$\alpha=\varepsilon=1-\rho$. The Duffie and Beckman approach [21] proved that the data generally available are measurements of reflectance i.e. the reflectance spectrum into segments and numerically integrate to obtain $\alpha_{\mathrm{s}}(0.3$ to $2.5 \mu \mathrm{m}$ corresponding to the wavelength interval of solar radiation impinging the terrestrial surface) or $\varepsilon_{\text {th }}(2.5$ to $25 \mu \mathrm{m}$ corresponding to the wavelength interval of emitted radiation by a blackbody at operation temperatures). The selectivity $\mathrm{S}$ is defined as the ratio of $\alpha_{\mathrm{s}}$ to $\varepsilon_{\mathrm{th}}$.

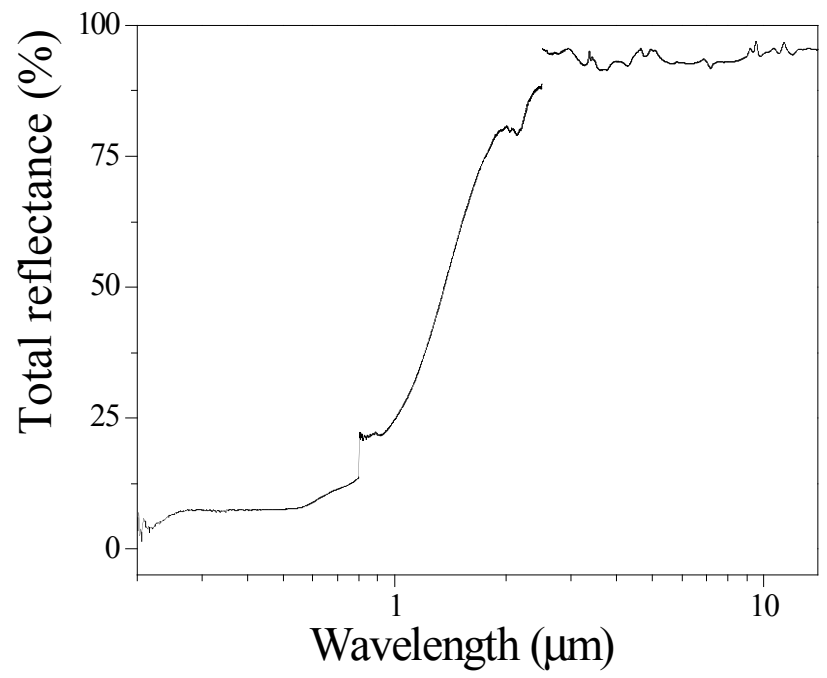

Fig. (6). Total spectral reflectance curve (0.2-14 $\mu \mathrm{m})$ for the coating of one dip into $\mathrm{Cu}$ substrate.

Table 1 summarizes the results of the obtained integrated solar absorbance and thermal emittance (at $373 \mathrm{~K}$ ), selectivity and root-mean-square, RMS. The solar absorption and the thermal emittance are in the range between $0.76-0.85$ and $0.05-0.10$, respectively, with improved selectivity of 15.2 for the coating with one dip. This means that the solar absorptance is relatively low compared to other selective surfaces $[2,21]$, but the thermal emittance is good enough, similar to the best selective thin films previously reported [2, 21]. Furthermore, increasing the number of dips, followed by an increase in thickness, has led to unfavorable detach of the film and increased emittance.

\section{CONCLUSIONS}

A black iron oxide, made-up of several nanoparticles, was prepared by a green chemical synthesis method in aqueous solution. In accordance with XRD and XPS studies, the prepared powder is $\mathrm{Fe}_{3} \mathrm{O}_{4}$ with 1:2 atomic stoichiometry between $\mathrm{Fe}^{2+}$ and $\mathrm{Fe}^{3+}$. The solution, containing $\mathrm{Fe}_{3} \mathrm{O}_{4}$ nanoparticles, is used to prepare thin film by dip process onto copper substrates. After drying, a homogeneous opaque black coating, well-adhered to the substrate surface, was obtained. The adhesion to metal substrate is attributed to the low crystallite size of $\mathrm{Fe}_{3} \mathrm{O}_{4}$. Good optical properties for efficient photo-thermal conversion of solar energy $\left(\alpha_{\mathrm{s}}=0.76-0.85\right.$ and $\left.\varepsilon=0.05-0.1\right)$ with optimized selectivity for the one layer dip are confirming the potentiality of $\mathrm{Fe}_{3} \mathrm{O}_{4}$ nanoparticles as a solar absorbing layer which is partially explained by the random surface roughness, the thickness of the film and, of course the intrinsic optical properties of $\mathrm{Fe}_{3} \mathrm{O}_{4}$. We believe this study find potential from the technological point of view, because the production of thin films of nanostructured iron oxide could be considered as a main step towards the straightforward formation of coating at room temperature for the development/design of solar collectors.

\section{ACKNOWLEDGEMENTS}

Financial support by CONACYT-Project 60781-Y is acknowledged.

\section{CONFLICT OF INTEREST}

None declared.

\section{REFERENCES}

[1] Tabor HZ. Receiver for solar energy collectors. U.S. 2917817, December 22, 1959.

[2] Wäckelgård E, Niklasson GA, Granqvist CG. Selectively solarabsorbing coatings. In: Gordon J, Ed. Solar Energy - The state of the art. London: James \& James (Science Publishers) Ltd. 2001; pp. 109-44.

[3] Kennedy C. E. Review of mid- to high-temperature solar selective absorber materials. Technical report. Report No: NREL/TP-52031267. Golden, CO: National Renewable Energy Laboratory 2002.

[4] Kennedy CE, Price H. Development and testing of hightemperature solar selective coatings. Conference paper, NREL/CP520-36581. National Renewable Energy Laboratory: Golden, CO 2005.

[5] Oelhafen P, Schüler A. Nanostructured materials for solar energy conversion. Solar Energy 2005; 79: 110-21.

[6] Etherden N, Tesfamichael T, Niklasson GA, Wäckelgård E. A theoretical feasibility study of pigments for thickness-sensitive spectrally selective paints. J Phys D: Appl Phys 2004; 37: 1115-22.

[7] Kang YS, Risbud S, Rabolt JF, Stroeve P. Synthesis and characterization of nanometer-size $\mathrm{Fe}_{3} \mathrm{O}_{4}$ and gamma- $\mathrm{Fe}_{2} \mathrm{O}_{3}$ particles. Chem Mater 1996; 8: 2209-11.

[8] Zhang DH, Liu ZQ, Han S, et al. Magnetite $\left(\mathrm{Fe}_{3} \mathrm{O}_{4}\right)$ core-shell nanowires: Synthesis and magnetoresistance. Nano Lett 2004; 4: 2151-5.

[9] Si SF, Li CH, Wang X, Yu DP, Peng Q, Li YD. Magnetic monodisperse $\mathrm{Fe}_{3} \mathrm{O}_{4}$ nanoparticles. Cryst Growth Design 2005; 5: 391-3.

[10] Chen R, Song G, Wei Y. Synthesis of variable-sized $\mathrm{Fe}_{3} \mathrm{O}_{4}$ nanocrystals by visible light irradiation at room temperature. J Phys Chem C 2010; 114: 13409-13.

[11] Vijayakumar R, Koltypin Y, Felner I, Gedanken A. Sonochemical synthesis and characterization of pure nanometer-sized $\mathrm{Fe}_{3} \mathrm{O}_{4}$ particles. Mater Sci Eng A 2000; 286: 101-5.

[12] Zhou ZH, Wang J, Liu X, Chan HSO. Synthesis of $\mathrm{Fe}_{3} \mathrm{O}_{4}$ nanoparticles from emulsions. J Mater Chem 2001; 11: 1704-9. 
[13] Cheng F. Y, Su CH, Yang YS, et al. Characterization of aqueous dispersions of $\mathrm{Fe}_{3} \mathrm{O}_{4}$ nanoparticles and their biomedical applications. Biomaterials 2005; 26: 729-38.

[14] Deng Y, Qi D, Deng C, Zhang X, Zhao D. Superparamagnetic high-magnetization microspheres with an $\mathrm{Fe}_{3} \mathrm{O}_{4} @ \mathrm{SiO}_{2}$ core and perpendicularly aligned mesoporous $\mathrm{SiO}_{2}$ shell for removal of microcystins. J Am Chem Soc 2008; 130: 28-9.

[15] $\mathrm{Xu} \mathrm{Z}$, Hou Y, Sun S. Magnetic core/shell $\mathrm{Fe}_{3} \mathrm{O}_{4} / \mathrm{Au}$ and $\mathrm{Fe}_{3} \mathrm{O}_{4} / \mathrm{Au} / \mathrm{Ag}$ nanoparticles with tunable plasmonic properties. J Am Chem Soc 2007; 129: 8698-9.

[16] Ai Z, Deng K, Wan Q, Zhang L, Lee S. Facile microwave-assisted synthesis and magnetic and gas sensing properties of $\mathrm{Fe}_{3} \mathrm{O}_{4}$ nanoroses, J Phys Chem C 2010; 114: 6237-42.

[17] Muenker AH, Young II AR. High temperature solar absorber coating and method of applying same. U.S. 4211210, 8 July 1980.

[18] Muenker AH, Young II AR. High temperature solar absorber coating and method of applying same. U.S. 4268319, 19 May 1981.
[19] Douglass DL, Pettit RB. The selective solar absorptance of in situgrown oxide films on metals. Solar Energy Mater 1981; 4: 383402.

[20] Rodriguez-Carbajal J. Laboratoire Leon Brilloin (CEACNRS): Saclay, France, 2006.

[21] Duffie JA, Beckman WA. Solar engineering of thermal processes $2^{\text {nd }}$ ed. New York: John Wiley \& Sons 1991.

[22] Nakamoto K. Infrared spectra of inorganic and coordination compounds. New York: Wiley-Interscience 1970.

[23] Mills P, Sullivan JL. A study of the core level electrons in iron and its three oxides by means of X-ray photoelectron spectroscopy. J Phys D: Appl Phys 1983; 16: 723-32.

[24] Fujii T, De Groot FMF, Sawatzky GA, Voogt FC, Hibma T, Okada K. In situ XPS analysis of various iron oxide films grown by $\mathrm{NO}_{2}$ assisted molecular-beam epitaxy. Phys Rev B 1999; 59: 3195-202.

[25] Barrera E, Gonzalez F, Rodriguez E, Alvarez-Ramirez J. Correlation of optical properties with the fractal microstructure of black molybdenum coatings. Appl Surf Sci 2010; 256: 1756-63.

Received: August 31, 2011

Revised: November 1, 2011

Accepted: November 6, 2011

(C) González et al.; Licensee Bentham Open.

This is an open access article licensed under the terms of the Creative Commons Attribution Non-Commercial License (http://creativecommons.org/licenses/by-nc/ 3.0/) which permits unrestricted, non-commercial use, distribution and reproduction in any medium, provided the work is properly cited. 